\title{
EXPLICATING STRUCTURAL REALISM IN THE FRAMEWORK OF THE STRUCTURALIST METATHEORY
}

\author{
Thomas Meier ${ }^{\ddagger}$
}

\begin{abstract}
A form of structural realism affirms that, when our theories change, what is always retained is their structural content and that there is structural continuity between our theories, even through radical theory change. I first introduce and discuss structural realism, with a focus on structural realism and change theory. Then, I will consider some critiques on structural realism. In order to address them, I introduce the framework of the so-called structuralist metatheory and allude to the notion of reduction, arguing that this notion provides the formal elucidation of the notion structural continuity. This aims to get a precise notion of continuity of structure, which is central to structural realism and to the understanding of theory change. In this sense, I propose a new way of formulating structural realism in an appropriate formal framework, namely, the framework of structuralist metatheory.
\end{abstract}

KEYWORDS: structural realism - theory change - structural continuity - structuralist metatheory reduction

\section{RESUMO}

Uma forma de realismo estrutural afirma que, quando nossas teorias mudam, o que sempre é retido é seu conteúdo estrutural e que há continuidade estrutural entre nossas teorias, mesmo com a mudança radical da teoria. Em primeiro lugar, apresento e discuto o realismo estrutural, com foco no realismo estrutural e na teoria da mudança. Depois, vou considerar algumas críticas ao realismo estrutural. Para abordá-las, introduzo o quadro da chamada metateoria estruturalista e faço alusão à noção de redução, argumentando que esta noção fornece a elucidação formal da noção de continuidade estrutural. Isto visa obter uma noção precisa de continuidade da estrutura, que é central para o realismo estrutural e para a compreensão da mudança teórica. Neste sentido, proponho uma nova forma de formular o realismo estrutural num quadro formal apropriado, nomeadamente, o quadro da metateoria estruturalista.

PALAVRAS-CHAVE: realismo estrutural - mudança de teoria - continuidade estrutural metateoria estruturalista - redução

\footnotetext{
\$Ludwig-Maximilians-Universität.thomas.meier@lrz.uni-muenchen.de. Perspectivas - Revista do Programa de Pós-Graduação em Filosofia da UFT - n. 2 - 2018
} 


\section{Introduction}

During the last decades, there have been several developments concerning a formulation of mainly two views within the debate on structural realism, so-called epistemic and ontic structural realism. The former affirms that all our knowledge is structural, but we remain ignorant with respect to the properties of the entities that are part of these structures. ${ }^{1}$ Ontic structural realism asserts that all that exists is structure. Following this view, objects only fill places in structures and do not exist independently at a fundamental level. The ontologically basic entities are structures. ${ }^{2}$

This work concentrates on a contribution to the development of the epistemic form of structural realism. In this work, I examine the central features of Worrall's (1989) original proposal of structural realism from the perspective of structuralist metatheory and argue that the former can be formulated in a novel way if we apply notions of the latter. I will argue that, by adopting the formal framework of structuralist metatheory, ${ }^{3}$ there is a way to formulate a new formal approach to structural realism, in particular to its epistemic formulation of it.

Since this work mainly concerns the issue of theory change and the persistence of structures through such a change, it is the epistemic version of structural realism which is addressed. I will further argue that the debate on ontic structural realism can be addressed independently of epistemic structural realism, and has its own problems that don't arise for epistemic structural realists.

To address some critiques of structural realism the framework of structuralist metatheory provides us with a developed methodology and the adequate formal tools for the logical reconstruction of empirical theories. The structuralist concept of reduction will play a central role here. In the last years, much has been said about the appropriate framework for structural realism. Especially in Landry and Rickles (2012), an abundant

\footnotetext{
${ }^{1}$ This position can be traced back to Poincaré (1905), Russell (1912), Carnap (1928) and Worrall (1989). Though the distinction between epistemic and ontic structural realism has been introduced later, Worrall is usually seen as an adherent of epistemic structural realism. This might be somehow misleading, since Worrall never argues that what we can know is the structure of the world, but what persists through theory change, are certain mathematical structures.

2 See Ladyman (1998) and French and Ladyman (2003) for the detailed outline of ontic structural realism. For a more recent and detailed work on this view, see also Ladyman and Ross (2007).

${ }^{3}$ This view is mainly associated with the works of Joseph Sneed (1971) and Wolfgang Stegmüller (1976). A detailed exposition of the formal framework of this approach is Balzer, Moulines and Sneed (1987). There is no full consensus on the name of this approach. It is often called structuralist program in the philosophy of science, or sometimes Sneed-Stegmüller Structuralism, Structuralist Metatheory or Metatheoretical Structuralism. I will adopt the name structuralist metatheory here.
}

Perspectivas - Revista do Programa de Pós-Graduação em Filosofia da UFT - n. 2 - 2018 
discussion concerning a framework for structural realism is presented. Other frameworks might work as well for this purpose, such as the Partial Structures Approach (henceforth PSA), ${ }^{4}$ but I will explore the possibilities of structuralist metatheory and defend them. I think one can be pluralistic up to some point within this context. What is needed is a formal framework that serves to explicate structural realism. We need a combination of a philosophical vision and such a formal framework, in order to do so. A Ramsey-view alone is not sufficient to explain structural continuity in a satisfying way. I will come back to this later. With respect to the choice of such a framework, I remain pluralistic, since for the purpose of modeling structural continuity, differences are only marginal. Both structuralist metatheory and PSA belong to the family of semantic conceptions of theories.

Many structuralist reconstructions of empirical theories out of different disciplines (like physics, chemistry, biology, economics, psychology, linguistics, sociology) have been worked out during the past decades..$^{5}$ A core part of logical reconstructions in the sense of structuralist metatheory is to demonstrate precisely which parts of the reconstructed theories under issue are connected to other theories, that is, to represent intertheoretical relations. I will claim that, whenever there is a structural continuity between two theories, structuralist metatheory provides the adequate formal tools to show precisely how such a structural continuity looks like, namely, by explaining this continuity applying notions from the formal framework of structuralist metatheory (like the notion of reduction, and possibly others) to it. However, as I already mentioned above, this does not imply that the framework of PSA is not suitable for the same purpose. In this sense, what Worrall originally meant by his appeal to the continuity of structure can be formulated in a more precise way. In this sense, this work is a programmatic proposal for how to approach structural realism within the debate on theory change. It is a proposal for the epistemic version of structural realism, concentrated on making precise sense of the notion of structural continuity, not restricting to equations or Ramsey-sentences.

\section{On epistemic and ontic structural realism}

Worrall's structural realism is introduced in the context of making use of both worlds, i.e. he aims to incorporate both, the No-Miracle-Argument (NMA), which goes back to Smart

\footnotetext{
${ }^{4}$ See Da Costa and French (2003) for a detailed outline of this approach. Also Bueno (1999, 2000, 2008 and 2009) discuss scientific change within the approach of PSA.

${ }^{5}$ See Diederich, Ibarra and Mormann (1989 and 1994) and Abreu, Lorenzano and Moulines (2013) for an overview of structuralist reconstructions

Perspectivas - Revista do Programa de Pós-Graduação em Filosofia da UFT - n. 2 - 2018
} 
(1963, 1979), Putnam (1975) and Boyd (1983), and the Pessimistic-Meta-Induction (PMI), which goes back to Laudan (1981), and to offer in consequence a new proposal to scientific realism, namely, structural realism. As is well known, NMA can be formulated as follows: Our empirical theories are successful. If our empirical theories are successful and our empirical theories are false, then it is a miracle that our empirical theories are successful. But it is not a miracle that our empirical theories are successful. Therefore, our empirical theories are true. PMI, on the other hand, relies on the history of science. Following this argument, it is likely that our present theories are false, given the huge amount of theories we once held true, and that later on turned out to be false.

Let us turn the discussion now to the distinction between OSR and ESR. I argue that OSR can be criticized independently of ESR. The adherents of OSR argue that at the fundamental ontological level, there are no objects, but structures. Probably the main objection to this view is that there can be no relations without relata, in other words "one cannot intelligibly subscribe to the reality of relations unless one is also committed to the fact that some things are related" (CHAKRAVARTTY, 1998, p. 399). So if it is only relations that there are, it can't be without having relata as a necessary constitutive part of the relations. However, some adherents of OSR offer the following answer to this problem:

The best sense that can be made of the idea of a relation without relata is the idea of a universal. For example, when we refer to the relation referred to by 'larger than', it is because we have an interest in its formal properties that are independent of the contingencies of their instantiation. To say that all that there is are relations and no relata, is therefore to follow Plato and say that the world of appearances is illusory (LADYMAN \& ROSS, 2007, p. 152).

We can see this answer as an example of how the OSR-debate has shifted away from ESR and generated its own problems. To argue like Ladyman and Ross do, is to move away into hard metaphysics, which is something entirely different from the focus on epistemic structuralism.

Another critical point is that OSR seems to be heavily grounded on contemporary physics. In ESR, what is central is the claim that what we can know is the structure of the world, to speak with Poincaré's famous quote:

Fresnel's theory enables us to do today as well as it did before Maxwell's time. The differential equations are always true ... they express relations, and if the equations remain true, it is because the 
relations preserve their reality. They teach us now, as they did then, that there is such and such a relation between this thing and that; only, the something which we then called motion; we now call electric current. But these are merely names of the images we substituted for the real objects which Nature will hide forever from our eyes. (POINCARÉ, 1905, pp. 160-161)

At no point, ESR-adherents claim that at the ontologically fundamental level, there are no objects. For an adherent of ESR, I include myself here, it can be perfectly fine to accept that at the ontologically fundamental level there exist objects. The crucial point is that we can't know them. What we can know, are the structures which describe the behaviour of these objects. These structures can be mathematical equations, scientific theories as a whole, Ramsey-sentences, model-theoretic structures, or something else.

Moreover, if we want to address Worrall's original proposal and if we want to contribute to the debate on scientific/structural realism and theory change, we need to work on ESR, since OSR does not have a concrete relation to this. The main questions about OSR do not bear with theory change, but with the foundations of physics, causality and the metaphysics of science. On the other hand, ESR is about the structure of our scientific theories, but OSR is about the structure of the world at its most fundamental ontological level.

In his original work, Worrall bases his position on a case study of optical theory. He mentions the theoretical change from Fresnel's to Maxwell's theory of optics. He states that, though the referents and names of the postulated entities in our theories change, the mathematical structure is preserved through theory change. Furthermore, what is continuous is the mathematical structure, that is, some equations that reappear in successor theories after theoretical change. Differential equations of Fresnel's theory of the ether reappear in Maxwell's theory of the electromagnetic field. Worrall illustrates this position:

Although Fresnel was quite wrong about what oscillates, he was, from this later point of view, right, not just about the optical phenomena, but right also that these phenomena depend on the oscillations of something or other at right angles to light. Thus if we restrict ourselves to the level of mathematical equations - not notice the phenomenal level - there is in fact complete continuity between Fresnel's and Maxwell's theories. (WORRALL, 1989, pp. 118-119) 
What is asserted by Worrall, is that our empirical theories are not completely overthrown when they change, the structural parts are retained. Nevertheless, it is not entirely clear on this point. Worrall argues that we do not notice the phenomenal level. But if we would not notice the phenomenal level, there would be no connection to the empirical anymore, it could be a purely mathematical structuralism, dealing with equations that are not attached to reality in any form. This is why it is important to note that the phenomenal level does also matter for the structural realist. But there can be important changes at this level, and still, there can be a structural continuity through theory change, even if the semantic status of the referents of the unobservable entities changes radically. It is central that, for the structural realist, we do not have epistemic access to the referents of the (unobservable) entities that appear in our empirical theories. But we can have knowledge of the mathematical structures (equations), in which these entities appear. If it occurs that the same equations are part of radically different theories, for the structural realist it seems reasonable to assume that what represents the world as best possible are these equations.

But equations should not be necessary for structural realism to work. Many mature scientific disciplines make no use of equations, or only very little (e.g. Linguistics, Biology, Social Sciences). Disciplines which deal more with qualitative concepts and are less mathematized need also be reconstructable from a structural realist perspective ${ }^{6}$. If this can't be done, structural realism cannot be taken as a serious position, unless one wants to be a strong reductionist about physics.

What we know in the discussion on structural realism, is that certain structures are preserved through theoretical change - see Worrall's case-study (1989) -, and that other parts of our theories get lost. Now, the underlying epistemologically fundamental idea behind this whole approach can be made explicit as follows: If only structure is preserved, and if we aim to be scientific/structural realists, only the structures can bear the connection to the world.

Since it is the structures that appear again and again through theoretical change, only these can transmit the real part of our theories. This just follows if we accept that all other parts of our theories (like the terms to which we refer with our theories) get lost through

\footnotetext{
${ }^{6}$ Biology, Linguistics, Economics and the other social sciences do use equations that describe statistical regressions. New theories in these fields need to recover these equations for well confirmed parts of old theories, just as physics does. And this is so even if one is not a strong reductionist since the statistics relate to higher level laws.

Perspectivas - Revista do Programa de Pós-Graduação em Filosofia da UFT - n. 2 - 2018
} 
time. So, the epistemic structural realist concludes: our best epistemological access to our theories is through its structures.

For Worrall, structural realism is defensible, for having shown that at least in the case of theory change from Fresnel's to Maxwell's theory, certain mathematical structures persist. However, this is not enough, since one representative case-study does not convince us about the existence of structural continuities in all areas of mature science. For epistemic structural realism to get strengthened, it is necessary that further representative case studies are carried out. The structural realist will have to find such structural continuities in many other cases of theory change. As I will show below, I aim to contribute to this by providing a case-study of theory change in linguistics. This will be done by the application of the formal framework of structuralist metatheory.

\section{Objections to structural realism}

The proposal of structural realism made by Worrall raised several objections. These objections have been presented especially by Stathis Psillos. ${ }^{7}$ I will shortly mention Psillos' objections (and others). The following list summarizes the objections which are relevant for my proposal in this work.

\subsection{The Standard-Realism Objection}

Psillos argues that the notion of structural continuity can be fully explained by standard scientific realism. Mathematical equations have been retained because they form an integral part of the approximately true theoretical content of theories. But furthermore, there needs to be some theoretical content beyond the equations. Psillos explains this as follows:

If the empirical success of a theory offers any grounds for thinking that some parts of a theory have 'latched on to' the world, those parts cannot be just some (uninterpreted) mathematical equations of the theory, but must include some theoretical assertions concerning some substantive properties as well as the law-like behaviour of the entities and mechanisms posited by the theory ... let me just stress the main point: if one admits that there is substantive (not just formal) retention at the structural-mathematical level, then one should admit that some theoretical content, too, gets retained. But

\footnotetext{
${ }^{7}$ See Psillos (2001 and 1999, pp. 146-161). There, he presents several objections to structural realism. My aim is only to address some objections, since it would not be possible to address all objections in one single paper.

Perspectivas - Revista do Programa de Pós-Graduação em Filosofia da UFT - n. 2 - 2018
} 
such an admission would undercut the claim that predictive success vindicates only the mathematical structure of a theory. (PSILLOS, 1999, p. 148)

And for Psillos, one would end up with the standard scientific realism picture again. As soon as one accepts more than pure mathematical structure, he is more than a structural realist, Psillos argues. Worrall seems to state that all that is preserved, are the equations. It is not so clear in which part of our theories the theoretical content enters. It is a part of our equations, but, as Psillos argues, there is also theoretical content that is not part of our equations. And if such content is preserved, we would get standard scientific realism again.

\subsection{The Uninterpreted-Structures Objection}

That certain structures are retained through theoretical change does not imply that these structures (as equations) tell us anything about the structure of the world. It is not clear whether these equations represent relations between physical entities which would be otherwise unknowable. The descriptions of the world, obtained through our empirical theories, cannot be only expressed by equations. Some theoretical assumptions which are not part of equations are also required in order to justify the success of an empirical theory. In Psillos' words: “... in empirical science we should at least seek more than formal structure. Knowing that the world has a certain formal structure (as opposed to natural structure) allows no explanation and no prediction of the phenomena" (PSILLOS, 2001, p. 21).

One might think in a first step that this sounds very much like the Standard-Realism objection. However, the Uninterpreted-Structures objection is different in the following sense. One can interpret equations in a merely instrumentalist setting, e.g. one can give purely technical explanations on how certain functions look like, but this does not commit her to scientific realism, since giving purely technical interpretations to mathematical structures does not imply any commitment the scientific realist wants to make.

\subsection{The Structure-Nature Objection}

The distinction between structure and nature of an entity, as Worrall proposes, has no justification. Following Psillos, scientists normally describe the nature of an entity by ascribing certain properties and relations to it. The nomological behavior is then expressed 
by some equations. There is no need for the distinction between structure and nature of an entity, since it is metaphysically inflationary. In Psillos' words:

Is the nature of a theoretical entity something distinct from its structure? Equivalently, can one usefully conceive of the physical content of a mathematical symbol (that is, of the entity or process it stands for) as distinct from the totality of the interpreted mathematical equations in which it features, (that is, from the totality of laws which describe its behaviour)? When scientists talk about the nature of an entity, what they normally do - apart from positing a causal agent - is to ascribe to this entity a grouping of basic properties and relations. They then describe its law-like behaviour by means of a set of equations. In other words, they endow this causal agent with a certain causal structure, and they talk about the way in which this entity is structured. I think that talk of 'nature' over and above this structural description (physical and mathematical) of a causal agent is to hark back to the medieval discourse of 'forms' and 'substances'. Such talk has been overthrown by the scientific revolution of the seventeenth century (PSILLOS, 1999, p. 149).

\subsection{The Structure-Loss Objection}

Chakravartty (2004), Bueno (2008) and others claim that there are not only cases of structural continuity, but also of structural loss through theory change. This objection relies on historical facts of theoretical change and is hard to reject at first sight. Bueno rightly refers to Laudan (1996), who first discussed such cases of structural-loss, before he says:

However, structural realism also faces a further difficulty. It arises not from the existence of different structures that do the same job, but from the existence of structural losses in scientific change. There are well-known cases that support the existence of these losses. For example, when we moved from Descartes's celestial mechanics to Newton's, the structure provided by Descartes's theory of vortices was entirely lost. The latter theory explained why the planets moved in the direction that they did, and this was an issue left unexplained by Newton's own theory. In other words, some structure was lost in this Case. (BUENO, 2008, pp. 223-224)

It is right that in the shift from Descartes' to Newton's celestial mechanics, there was a loss of structure. Below, we will see how one can counter this objection, or at least turn it into the favour of the structural realist that aims to apply structuralist metatheory in the debate on structural realism. 


\subsection{An open question}

Not an objection, but an open question in the debate is the following, formulated by Frigg and Votsis (2011):

How does the exact relation of correspondence between two structures, the one in the abandoned and the one in the successor theory, look like?

In other words, the question Frigg and Votsis ask is about the form of intertheoretical relations between the theories in question, and about how such relations between the structures of the theories in question looks like in a formal sense. In the Fresnel-Maxwell case, how does the formal relation between Fresnel's and Maxwell's equations look like, since Fresnel's theory is the abandoned one and Maxwell's theory is the successor theory. It is clear that this question can only be answered by working out careful and detailed case studies, where the logical structure of the theories in question is reconstructed. It is exactly here where I will argue that structuralist metatheory has the adequate formal tools for explicating this open question.

The matter of correspondence between the two structures is closely connected to some of the objections I mentioned. First, if we are able to explicate formally how such a correspondence looks like, we can refer to that relation of correspondence as the structure that guarantees a continuity between both theories. This structure is not just an uninterpreted one, since it will hold between two concrete empirical theories. Second, the explication of such a relation will also serve to show how a structural loss is not affecting structural realism. For this to work, of course, it is required that the correspondence relation between two structures includes all relevant facts of both theories. I will come back to the discussion of structural losses when I give my answers to all objections in conclusion.

In the next sections, we will show how these critiques and open questions to structural realism can be addressed by applying the framework of structuralist metatheory to it. I argue that it will be at least possible to clarify it and to show a clear way of how to address structural realism with the focus on theory change and the persistence of structures, within the framework of structuralist metatheory. 


\section{Explicating structural realism}

\subsection{The Ramsey-sentence and partial structures}

Before I start my explication of structural realism by analyzing it within the framework of structuralist metatheory, I want to argue why I see this step as progressive in the debate. The main reason for this is that an approach in terms of the Ramsey-sentence does not suffice to capture structural continuities adequately. One can represent the structure of an empirical theory in terms of a Ramsey-sentence, but it is not nearly as expressive as it would be in terms of the semantic conception. The main problem for the Ramsey-view is that it is not developed to show the dynamics of theories. It is of course a tenable view if we aim to represent the structure of our theories, but for the modeling of theory change, it seems to be too limited. Let us quickly recall the Ramsey-sentence: Given an empirical theory with theoretical and observational terms: $\operatorname{TC}\left(t_{1}, \ldots, t_{n}, o_{1}, \ldots, o_{m}\right)$, we substitute the terms for variables and existentially quantify over them: $\exists x_{1}, \ldots, \exists x_{n} \mathrm{TC}\left(x_{1}, \ldots, x_{n}, o_{1}, \ldots\right.$, $\left.o_{m}\right)$. The Ramsey-sentence, as Worrall and Zahar (2001) argue, gives us a sufficient representation of the cognitive content of a theory. However, it is not entirely clear how a Ramsey-view representation of our theories in question could provide a representation of structural continuity. Nevertheless, Zahar is clear in how such a representation should look like:

Whereas referential continuity demands that as we move from one hypothesis to the next, we continue to talk about roughly the same objects, structural continuity more reasonably requires that we talk, in similar terms, about one thing-in-itself which is not directly accessible to us... there ought to be a translation of the old system into the new one such that all observational functions and predicates remain unchanged, and the old axioms are transformed into theorems, or else into limiting cases of theorems of the new theory. (ZAHAR, 2001, p. 54)

One could approach the debate better within the framework of the semantic conception of theories, as PSA, or with the framework of structuralist metatheory. Especially because of the sophisticated development of these frameworks, one can in each case make formally explicit, how a structural continuity between two theories looks like. In PSA, this explication could be in terms of partial morphisms, holding between the structures that 
represent the theory in question. ${ }^{8}$ In PSA, scientific change is represented by partial morphisms between structures that represent our theories in question. Let us recall the notion of Partial Isomorphism - see Da Costa and French (2003), among others: A partial structure is an ordered pair $\left\langle D, R_{i}\right\rangle_{i \in I}$, where $D$ is a non-empty set and $\left(R_{i}\right)_{i \in I}$ is a family of partial relations defined over $D$. Partial relations are characterized as triples $\left\langle R^{1}, R^{2}, R^{3}\right\rangle$, where $R^{1}, R^{2}, R^{3}$ are mutually disjoint sets, with $R^{1} \cup R^{2} \cup R^{3}=D^{n}$. And $R^{1}$ is the set of $n$ tuples that belong to $R$. $R^{2}$ is the set of $n$-tuples that do not belong to $R$, and $R^{3}$ is the set of $n$-tuples for which it is not defined whether they belong or not to $R$. There is only a partial preservation of structure. To model this, the notion of partial isomorphism is developed: Let $S_{1}=\left\langle D, R_{i}\right\rangle$ and $S_{2}=\left\langle D^{\prime}, R_{i}^{\prime}\right\rangle$ be two partial structures, where $R_{i}=\left\langle R_{1}, R_{2}, R_{3}\right\rangle$ and $R^{\prime}{ }_{i}$ $=\left\langle R_{1}^{\prime}, R_{2}^{\prime}, R_{3}^{\prime}\right\rangle$ are partial relations.

A partial function $f: D \rightarrow D^{\prime}$ is a partial isomorphism between $S_{1}$ and $S_{2}$ if:

(i) $f$ is bijective

(ii) for every $x$ and $y \in D, R_{1} x y \leftrightarrow R^{\prime}{ }_{1} f(x) f(y)$ and $R_{2} x y \leftrightarrow R_{2}^{\prime} f(x) f(y)$.

We can see that with the tools of PSA, we can model scientific change easily. While I can see the advantages of PSA over a Ramsey-view, I see it also as a weakness of PSA that its adherents do not focus on carrying out detailed reconstructions of cases of theory change. Their framework would allow a detailed representation of such cases. In this sense, PSA is a promising approach for the purpose of my proposal, but I argue that structuralist metatheory serves even better, since there is a focus in case studies about the dynamics of our theories. Since structuralist metatheory has also a precise criterion for theoretical terms, I see its framework as more appropriate for the purpose of explicating structural realism.

\subsection{Structuralist metatheory}

Let us now have a look at the framework of structuralist metatheory and how the notion of structural continuity can be explicated within this framework. In structuralist metatheory, an empirical theory consists of its models, which are sequences of the following form: $\left\langle D_{1}\right.$,

\footnotetext{
${ }^{8}$ A proper comparison of both PSA and structuralist metatheory should be the goal of a different paper. In the scope of this work, I only want to make clear that both approaches seem to be suitable for making the notion of structural continuity explicit.

Perspectivas - Revista do Programa de Pós-Graduação em Filosofia da UFT - n. 2 - 2018
} 
$\left.\ldots, D_{m}, R_{1}, \ldots, \mathrm{R}_{n}\right\rangle$. The $D_{i}$ are so-called basic sets and the $R_{j}$ are relations constructed on these sets. The $D_{i}$ contain what is taken to be the ontology of the theory, i.e. they contain the objects assumed by the theory as real. Note that these objects are part of a structure. The existence of the entities which are taken to be the elements of the basic domains of our structures is merely a posit. It is noteworthy that also in structuralist metatheory, objects do only exist within these domains, which are itself a constitutive part of a structure and specified by the $R_{j}$, which are usually functions. In empirical theories which make use of quantitative tools, they usually are functions mapping empirical objects into the real numbers, or some other mathematical entities. Structuralist metatheory makes use of settheoretic predicates, relying on Suppes (1957) original proposal.

A set-theoretic predicate $P$ specifies the following:

- The type of a structure $\left\langle D_{1}, \ldots, D_{m}, R_{1}, \ldots, \mathrm{R}_{n}\right\rangle$ in determining the number $k$ of base sets and the number $n$ of relations;

- The typification of the relations $R_{1}, \ldots, \mathrm{R}_{n}$;

- The axioms that the relations $R_{1}, \ldots, \mathrm{R}_{n}$ need to satisfy for the structure $\left\langle D_{1}, \ldots, D_{m}\right.$, $\left.R_{1}, \ldots, \mathrm{R}_{n}\right\rangle$ to be an instance of the set-theoretic concept $P$.

More specifically, in structuralist metatheory, a theory is understood to consist of the following sets of models: A set of potential models $\left(M_{\mathrm{p}}\right)$ fixes the general framework, in which an actual model of a theory is characterized. All entities that can be subsumed under the same conceptual framework of a given theory are members of the sets of the potential models of this theory. Let's consider an example of such a potential model, expressed as a set-theoretic predicate, which makes the structure of an empirical theory explicit.

The example of a potential model, the potential model $M_{p}$ of Classical Collision Mechanics, see (BALZER; MOULINES \& SNEED, 1987, pp. 26-27):

1. $M_{\mathrm{p}}=\langle P, T, \mathbb{R}, v, m\rangle$

2. $P$ is a finite, non-empty set

3. $T$ contains exactly two elements

4. $v: P \times T \rightarrow \mathbb{R}^{3}$

5. $m: P \rightarrow \mathbb{R}^{+}$ 
$P$ is a set of discrete bodies (that can be called "particles"), $T$ is a set of instants. $v$ is the velocity function, assigning to each particle $p$ and point of time its velocity as an element of $\mathbb{R}^{3}$. Velocity is a time-dependent vectorial function whose range are triples of real numbers. It assigns a three-component vector (one component for each direction in space) to each particle at each time. $m$ is the mass function, assigning to each particle its mass.

Sets of partial potential models $\left(M_{\mathrm{pp}}\right)$ represent the framework for the corroboration or refutation of the theory in question, they represent the framework of data, which shall corroborate or refute a theory. The concepts in $M_{\mathrm{pp}}$ can be determined independently of $T$. Terms which are theoretical (and proper to $T$ ) in the potential models of the respective theory are cut out. In other words, this means that partial potential models are the pure data-models within the structuralist framework. These sets of models do not contain any theoretical terms or functions, no concepts which are introduced properly by a theory.

Sets of models which do not only belong to the same conceptual framework, but also satisfy the laws of the same theory are called the sets of actual models $(M)$ of a theory.

The example of an actual model, (BALZER; MOULINES \& SNEED, 1987, p. 27): $x$ is an actual model of classical collision mechanics $(x \in M(\mathrm{CCM}))$ if and only if there exist $P, T, \mathbb{R}, v, m$ such that:

1. $x=\langle P, T, \mathbb{R}, v, m\rangle$;

2. $x \in M_{\mathrm{p}}(\mathrm{CCM})$

3. $\sum_{p \in P} m(p) \cdot v\left(p, t_{1}\right)=\sum_{p \in P} m(p) \cdot v\left(p, t_{2}\right)$ :

In the actual model of CCM, the fundamental law of this theory is added, the law of conservation of momentum, expressing that the sum of the products of mass and velocity of each particle must remain the same before and after a collision. Furthermore, it is a fact that local applications of a scientific theory may overlap in space and time. For this purpose, the formal notion of global constraint is introduced. The sets of global constraints $(G C)$ are formal requirements that restrict the components of a model in dependence of other components of other models. Constraints express physical or real connections between different applications of a theory, i.e. the inner-theoretical relations. To explain it intuitively, think of a physical object that is part of a system. This object, say, a certain 
train waggon, must have the same weight, no matter to which physical system that waggon belongs. It may stand on a railroad somewhere in Nebraska, or on a railroad close to Berlin. The same waggon will have the same weight, if we think of physical systems on earth. This fact cannot be overseen. Because of such overlaps, the notion of constraint is required in structuralist metatheory.

Some empirical theories deal with the same or very similar domains of objects. Particles will have the same mass in Classical Collision Mechanics and in Classical Particle mechanics. Anyhow, these are different theories. The sets of global links (GL) represent the intertheoretical connections between such theories.

1. An empirical theory $T$ consists of its core $K$ and of the intended applications $I . K$ is itself a complex structure and consists of sets of potential models $M_{\mathrm{p}}$, partial potential models $M_{\mathrm{pp}}$, actual models $M$, global constraints $G C$ and the global links GL.

2. The $I$ are the sets of the intended applications of a theory. These are not formally characterized. Their determination depends on pragmatic constraints.

3. A theory-element is then, formally, the following tuple: $T=\langle K, I\rangle$; where $K=\left\langle M_{\mathrm{p}}\right.$, $\left.M_{\mathrm{pp}}, M, G C, G L\right\rangle$.

One central methodological claim of structuralist metatheory is that, after a logical reconstruction of some theories under issue, we gain results about their relations to other theories. In the intertheoretical relations, it is possible to identify structures that might appear in both related theories. The respective potential models (i.e. their general frameworks) of different theory-elements can be related through such relations. Such intertheoretical relations can count as one version of structural continuity. In the FresnelMaxwell case, the continuity would be that some differential equations appear in both the older and in the successor theory.

What could be said against this proposal is that, from the fact that certain intertheoretical (and inner-theoretical) relations can be shown, it does not follow that these structures are in any form real. But if these structures persist again and again during radical theory change, this tells us that at least that our formal representation of the persisting structures reflects the world correctly. The parts of a structure which would persist, would 
then show that we got at least something of the world right. This cannot be the entities as objects, since the referents of the objects of our theories can change radically.

Of course, the persistence of these structures needs to be linked somehow to the empirical level, i.e. the structures need to be empirically grounded. Within the approach of structuralist metatheory, this occurs only if one builds such structures up, based on concrete empirical theories. This means that the formal structures are always a metatheoretical representation of a concrete empirical theory. We will see more concretely how this looks like, when we consider an example of structural continuity in the next section.

As it is a general aim of this work to outline the methodological framework of structuralist metatheory and to show its relations and its applicability to structural realism, it is important to outline that Sneed mentions the relation between scientific realism and structuralist metatheory in the following way:

It is important to understand that, on the structuralist view, empirical theories do make straightforward, descriptive, falsifiable claims about their subject matter. Structuralism is not just a new version of instrumentalism hiding behind a cloud of set-theoretic notation. On the other hand, structuralists see the mathematical structures associated with a theory to be much more essential features of the theory than the claims it makes. The claims may change with the historical development of the theory, but the mathematical apparatus remains the same. Thus both structuralist and realist would agree that empirical science makes descriptive claims but disagree about the extent to which empirical scientists, speaking professionally, mean what they say. (SNEED, 1983, p. 351).

Sneed explicitly states that some claims of our theories may change through history, but that the mathematical apparatus remains the same. This, I argue, must be seen as closely related to the structural realist notion of structural continuity through theoretical change, as Worrall claims it. Sneed in fact endorses a structural realist view here. But as mentioned above in the case of Worrall (1989), the phenomenal level and its connection to the structures that supposedly represent it needs to be included. In fact, what Sneed proposes here sounds strongly like structural realism, but it is only tenable if the role of the phenomenal level becomes clear.

In structuralist metatheory, the usual approach is to reconstruct some representative empirical theories logically. By doing so, the aim is to provide clarity about the logical 
structure and the ontological commitments of the reconstructed theory. Reconstructions show the logical structure of scientific theories. These are identified with structures in the above mentioned formal sense. When doing so, the methods of structuralist metatheory contribute to a clarification of structural realism. For they enable us to show what structural connections between empirical theories look like logically.

In this sense, the somehow too restricted or insufficient approach of Worrall, which is only about mathematical structure in the sense of equations (in the sense of the Ramseysentence), can be abandoned or, even better, amplified. Despite the fact that structuralist metatheory has been formulated principally as a program for outlining the logical structure of our empirical theories and to model the dynamics of scientific theories, and that it is usually understood as being neutral to debates on scientific realism, ${ }^{9}$ the acceptance of its framework as an instrument for logically reconstructing our empirical theories, combined with the epistemological assumption made above, lead to a form of structural realism. The structural realist can see herself strengthened in a significant way, once she adopts the framework of structuralist metatheory. However, one can still be a representative of structuralist metatheory without committing herself to structural realism. The step of accepting both structural realism and structuralist metatheory requires the acceptance of the above mentioned two epistemological assumptions.

\subsection{Structural continuity in the structuralist framework}

In order to represent structural continuities between our theories, I propose to make use of the structuralist concept of reduction, as it is discussed and defined by Díez and Moulines (see 2008, pp. 391-96):

Definition: Let $M_{\mathrm{p}}(T), M(T), I(T)$ respectively be the sets of potential models, actual models and intended applications of $T$.

Analogously, let $M_{\mathrm{p}}\left(T^{*}\right), M\left(T^{*}\right), I\left(T^{*}\right)$, with respect to $T^{*} . T$ is reducible to $T^{*}$ iff there exist the relations $\rho$ and $\rho_{\mathrm{e}}$ such that:

1. $\rho \subseteq M_{\mathrm{p}}(T) \times M_{\mathrm{p}}\left(T^{*}\right)$.

\footnotetext{
9 This has been made clear to me in personal conversation with Wolfgang Balzer and also with Pablo Lorenzano, Jose Díez and Ulises Moulines, all being representatives of this view. Although it should be the task of a proper investigation whether structuralism can really be a neutralist position. Especially, if one thinks of Stegmüller's notion of the relativized a priori, which seems to incline into a type of structural realism. This question will have to be addressed in a different work.
}

Perspectivas - Revista do Programa de Pós-Graduação em Filosofia da UFT - n. 2 - 2018 


$$
\begin{aligned}
& \text { 2. } \forall x, x^{*}\left(\left\langle x, x^{*}\right\rangle \in \rho \wedge x^{*} \in M\left(T^{*}\right) \rightarrow x \in M(T)\right) . \\
& \text { 3. } \forall y\left(y \in I(T) \rightarrow \exists y^{*}\left(\left\langle y, y^{*}\right\rangle \in \rho_{\mathrm{e}} \wedge y^{*} \in r\left[M\left(T^{*}\right)\right] \rightarrow y \in r[M(T)]\right)\right) .
\end{aligned}
$$

The first condition establishes that both theories are connected through their conceptual frameworks, their sets of potential models. Condition two expresses the derivability of laws from the reducing theory $T^{*}$ to the reduced theory $T$. And condition three expresses the preservation of the successful applications of the theories, where $\rho_{\mathrm{e}}$ is the relation $\rho$ at the $T$-non theoretical level.

I want to propose that, if two theories are related through the structuralist reduction relation, it can be seen as a case of a structural continuity. This criterion of structural continuity is of course not a necessary one, but sufficient. It would be absurd to claim that all cases of structural continuity should be cases of theory-reduction. As examples of reduction in the structuralist framework, one can consider the cases of the reduction of Classical Collision Mechanics to Classical Particle Mechanics, and the reduction of Rigid Body Mechanics to Classical Particle Mechanics shown in Balzer, Moulines and Sneed (see 1987, pp. 255-84).

\subsection{An example of structural continuity - theory change in linguistics}

As an example of structural continuity, I will discuss a case of reduction in linguistics. The relation of reduction between theories will be taken as an exemplar case of structural continuity. This continuity is expressed in the reduction relation as defined in the framework of structuralist metatheory.

Before the development of transformational grammar in the late nineteen-fifties of the twentieth century by Zellig Harris and later Noam Chomsky, structural linguistics was the paradigm. One main figure in structural linguistics, in its mature form, was Leonard Bloomfield. ${ }^{10}$ If structural realism wants to be explicated, it is only by carrying out case studies of all fields of mature science, how the question of structural continuity can be definitely answered. The case of linguistics is important for this purpose, since linguistics has become a mature science at least since the Chomskyan revolution, where a first

\footnotetext{
${ }^{10}$ Structural linguistics has its roots in Europe and is normally traced back to Ferdinand de Saussure, as its main developer, amongst many others. However, for the development of transformational grammar, Bloomfield's structural linguistics is more relevant, since Bloomfield was the main figure of linguistics in America in the first half of the twentieth century.

Perspectivas - Revista do Programa de Pós-Graduação em Filosofia da UFT - n. 2 - 2018
} 
important step towards mathematization was provided and a significant step concerning the explanatory power of linguistics could be made. This holds especially for the linguistic discipline of syntax.

Since Zellig Harris was the predecessor and teacher of Chomsky and the pioneer of transformational grammar, it becomes a natural question for the philosophy of science to ask whether there has been a structural continuity through this apparently revolutionary phase of theoretical change, namely, the phase of change from the paradigm of structural linguistics to transformational grammar, and shortly after to generative transformational grammar. Bloomfield already mentioned what was systematized later by Harris: That certain morpheme-classes correctly combined build up a grammatical sentence. In his words: "Each position in a construction can be filled only by certain forms" (BLOOMFIELD, 1926, p. 158). We can think of the example: The tree is old. as opposed to The _ is old. In the empty slot, only certain classes of morphemes (or forms) can occur. In this case, certain noun-classes. Bloomfield is also clear on the notion of substitution:

A substitute is a linguistic form or grammatical feature which, under certain conventional circumstances, replaces any one of a class of linguistic forms . . . thus, in English, the substitute ' $I$ ' replaces any singular-number substantive expression, provided that this substantive expression denotes the speaker of the utterance in which the substitute is used ... the substitute replaces only forms of a certain class, which we may call the domain of the substitute; thus, the domain of the substitute ' $I$ ' is the English form-class of substantive expressions. (BLOOMFIELD, 1933, p. 247)

Harris wanted to go further than Bloomfield and searched for a systematization of sentence-types. By doing so, he developed a method that enabled linguists to describe how sentences are built and changed, like from active to passive. These changes he called transformations. He introduced a formalism to label different types of phrases: noun phrases $(N)$, verbal phrases $(V)$, prepositional phrases $(P)$, the transformation arrow $(\leftrightarrow)$, etc. His notion of kernel sentence becomes central for this enterprise: "The kernel is the set of elementary sentences and combiners, such that all sentences of the language are obtained from one or more kernel sentences (with combiners) by means of one or more transformations" (HARRIS, 1957, p. 335).

We can think of an elementary sentence as follows: John saw Jill. Furthermore, Harris states "Our picture of a language, then, includes a finite number of actual kernel 
sentences, all cast in a small number of sentence structures built out of a few morpheme classes by means of a few constructional rules; a set of combining and introducing elements; and a set of elementary transformations" (HARRIS, 1957, p. 339). Following Harris, sentences like: John saw Jill, The cat sits on the mat, The tree is old, etc. are examples of such kernel sentences. To see a transformation as introduced by Harris, we can think of the following example:

- The kernel sentence: John saw Jill, in active is obtained from the passive

Jill was seen by John, through a transformation.

Harris' formalism in this case: $N_{1} V N_{2} \leftrightarrow N_{2} V^{*} N_{1}$.

For Harris, morphemes could be grouped into classes (e.g. the class of sufixmorphemes, e.g. -hood, etc.). The members of a class have similar sets of co-occurrents (here: neighbour-, false-, likeli-, etc. Each class occurs with specific other classes to make a sentence structure. Furthermore, certain sequences of classes could build up sentences. These sequences are products of a small number of elementary class sequences (constructions) which are combined in certain ways. As here: TNPNV (= The risk of crisis vanished) results from the more elementary class sequences $T N V$ and $N P N$.

The notion of form is central for Bloomfield: "The vocal features common to same or partly same utterances are forms; the corresponding stimulus-reaction features are meanings. Thus a form is a recurrent vocal feature which has meaning, and a meaning is a recurrent stimulus-reaction feature which corresponds to a form" (BLOOMFIELD, 1926, p. 155). Forms are non-observational, as opposed to utterances, with which the empirical linguist is acquainted when she actually works descriptively. The components of words, in their minimal occurrence, the morphemes, are forms. Following Bloomfield, a form is then any vocal feature which frequently is uttered and which is at least partially alike to further utterances. I introduce the set $\mathfrak{F}$ of forms.

I will quickly introduce both the potential models of Bloomfield's and of Harris theories of syntax. I restrict here to syntax because there, structural continuity is most eminent. The study of the complete logical structure of both theories is far more complex 
and requires an investigation on its own, and can not be part of this work. For the purpose of this work, it is sufficient to outline that both theories are related through the structuralist reduction-relation, concerning the linguistic sub-discipline of syntax.

The model $M$ of Bloomfield's syntax TBS:

1. $M=\langle\mathfrak{F}$, concat, ㄷ $\rangle$.

2. $\mathcal{F}$ is a finite, non-empty set.

3. concat: $\mathfrak{F}^{\infty} \times \mathfrak{F}^{\infty} \rightarrow \mathfrak{F}^{\infty}$.

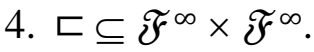

5. $\forall x$ ( $x$ is a form) $\rightarrow \exists y$ ( $y$ is a form and $y$ can be concatenated with $x$ ).

Basic intended interpretation: $\mathfrak{F}$ is a set of linguistic forms. The more specific linguistic entities such as morphemes, words, phrases or sentences, are all linguistic forms. Hence, only forms are required in the ontology of the theory. Several linguistic forms can be concatenated. We introduce the function concat: $\mathfrak{F}^{\infty} \times \mathfrak{F}^{\infty} \rightarrow \mathfrak{F}^{\infty}$. This is the concatenation function on forms, where $\left(\mathfrak{F}^{\infty}=\left\{\left\langle f_{1}, \ldots, f_{n}\right\rangle \mid f_{i} \in \mathfrak{F}, n \geq 1\right\}\right)$. We want to express that two or more linguistic forms can be combined in order to build bigger linguistic forms. Morphemes, for instance, are connected and construct bigger forms like words. These then can be connected to build up bigger forms, like phrases. Hence, we introduce an ordering relation on the set of linguistic forms. We call this the parthood relation for forms. It is a reflexive, antisymmetrical and transitive relation. As an example, we can think of the word 'unspeakable' which we can decompose into the three morphemes 'un', 'speak' and 'able'. By concatenating these three morphemes, the word 'unspeakable' is built.

The model $M$ of Harris' syntax THS:

1. $M=\langle\mathfrak{F}$, concat, ᄃ, trans $\rangle$.

2. $\mathcal{F}$ is a finite, non-empty set.

3. concat: $\mathfrak{F}^{\infty} \times \mathfrak{F}^{\infty} \rightarrow \mathfrak{F}^{\infty}$.

4. ᄃᄃ $\mathfrak{F}^{\infty} \times \mathfrak{F}^{\infty}$.

5. trans: $\mathfrak{F} \rightarrow \mathfrak{F}$.

6. $\forall x$ ( $x$ is a form) $\rightarrow \exists y$ ( $y$ is a form and $y$ can be concatenated with $x$ ).

Perspectivas - Revista do Programa de Pós-Graduação em Filosofia da UFT - n. 2 - 2018 
7. $\forall x(x$ is a form $) \rightarrow \exists y(y$ is the transform of $x)$.

The potential model of Harris' theory states the same as the model of Bloomfield, but expresses one more crucial fact, the fact that linguistic forms do always have a transform. The function trans expresses that forms are always transformed to other forms. This aims to adequately represent cases like the active-passive transformation, where an active sentence like John saw Jill, in active is obtained from the passive Jill was seen by John, through a transformation.

Now, structural continuity between TBS and THS is expressed through the reduction of $T B S$ to $T H S$, in the following reduction relation $\rho$ :

1. $\rho \subseteq M(\mathrm{THS}) \times M(\mathrm{TBS}),\left\langle x^{*}, x\right\rangle \in \rho$, iff:

2. $x^{*}=\langle\mathfrak{F}$, concat, ᄃ, trans $\rangle \in M(\mathrm{THS})$

3. $x=\left\langle\mathfrak{F}^{\prime}\right.$, concat', $\left.\check{C}^{\prime}\right\rangle \in M(\mathrm{TBS})$

4. $\mathfrak{F}=\mathfrak{F}^{\prime}$, concat $=$ concat,$\sqsubset \sqsubset=\sqsubset^{\prime}$

5. $\forall x(x$ is a form $) \rightarrow \exists y$ ( $y$ is a form and $y$ can be concatenated with $x$ ).

6. $\forall x(x$ is a form $) \rightarrow \exists y(y$ is the transform of $x)$.

Condition one states that the models of both theories are related through the reduction relation $\rho$, where in condition two and three, $x^{*}$ and $x$ are one set of the actual model. In four, it is expressed that the entities of both theories are identical, both theories deal with the same entities, namely, linguistic forms and their combination. Condition five expresses the syntactic law of both theories, that every form can be concatenated with another form. The new law, which makes THS the reducing theory over TBS, is expressed in condition 6 , where it is stated that every form has a transform, such as the example sentence John saw Jill. We have seen that in our case-study, Bloomfield's theory is reduced to Harris' theory. But the important fact for structural realism is that, the structure of Bloomfield's theory is completely overtaken and continuous with the structure of Harris' theory. It is just that Harris' theory is more complex, it has one law that is not part of Bloomfield's theory, but all other parts of the structure of TBS are continuous with THS. It is a structural continuity for the following reason. Both theories are represented as structures themselves. Now, the reduction relation provides the continuity of structure. 
Structuralist metatheory provides tools for a clarification of the notion of structural continuity. Empirical theories are taken to be structural entities themselves (in the formal sense explained above). Some information about intertheoretical relations (called links) or reductions might be trivial and not really informative. Anyhow, I argue, the structuralist framework provides formal notions for capturing all kinds of structural continuities, trivial and non-trivial.

When Worrall mentions the continuous appearance of certain equations in different theories, structuralist metatheory provides us with a far more universal and abstract notion of structural continuity of more sophisticated and detailed formal explanatory power. The notion of structural continuity, in this case, has the form as in the definition of the reduction above. But in each particular reconstruction of an empirical theory, a theory-net will have a certain structure. In this sense, when a theory has reached sufficient development and sophistication, it is possible to identify a structural continuity of some form. The important question is whether there is a relation of structural continuity which provides us with any important information concerning questions on theory change and structural realism. In the case of Bloomfield and Harris, it is the structure of their theories of syntax, that is preserved. As I have showed in the reduction relation above, Harris' theory adds more features to the theory, but all structures in Bloomfield are continuous with those in Harris.

The mentioning of the structuralist concept of reduction in this work should be understood as a simple illustrative example in order to promote the idea of approaching structural realism by applying the framework of structuralist metatheory to it. It is clear that the whole framework of structuralist metatheory offers a whole series of more complex and generally richer concepts which all might be perfectly well applicable to address the structural realist concern for structural continuity. ${ }^{11}$

\section{Responses to the objections on structural realism}

Finally, I want to propose the following answers to the above mentioned objections to structural realism. First, I argue that the Standard-Realism Objection is blocked if we accept the framework of structuralist metatheory. In the case of the reduction from Bloomfield to Harris, there are not even equations that could be part of these theories. This

\footnotetext{
${ }^{11}$ Especially Moulines (2011) introduced the notions of embedding and replacement. Whether these can also serve to describe structural continuities on a metatheoretical level is up to future inquiries.

Perspectivas - Revista do Programa de Pós-Graduação em Filosofia da UFT - n. 2 - 2018
} 
makes it such an important case, for if structural realism wants to be a tenable position, it should be applicable to all domains of empirical science, and not only to physics, or to sciences that have equations as a necessary part of them. By equations I mean differential equations, as they appear in physics, for instance. But generally, there cannot be a need for mathematical equations (in the sense of differential equations) for structural realism to make sense.

What about linguistics, again? I do not think it is necessary to have such equations to make sense of structural realism. But of course, the more mathematized a scientific discipline becomes, the easier it gets for structural realism to sort out relevant structures that can become relevant for the discussion on structural continuity. A tree, as it appears in the constituent analysis of syntax-theory is also a mathematical structure, and henceforth it enters into the discussion on structural realism.

My answer to the first objection goes very much along with my answer to the next objection. To the Uninterpreted-Structures Objection, I propose that if we approach structural realism with the framework of structuralist metatheory, we will not only talk about equations as structures, but of the whole empirical theories as structures. We will never have the problem of having only uninterpreted structures, if we rely on structuralist reconstructions of real empirical theories. In the case of TBS and THS, the structures of both theories are not uninterpreted, for they represent real physical entities, namely, linguistic forms, and the ways in which they are put together. It is important to mention that linguistic forms, as existing physical entities, have to be understood as tokens, just analogous to physics. When physicists measure the movement of electrons, they measure tokens, but when a theory about electrons is formulated, it is about types. This is the same case in linguistics. Within a theory, forms are types, but as entities, measured in a physical system (in this case, a natural language), they are tokens.

The Structure-Nature Objection, I argue, can be answered in a Carnapian way, if we think of the Aufbau, where Carnap explains the distinction between structure and nature, where he calls it the material:

Every scientific statement can in principle be so transformed that it is only a structural statement. ... For science wants to speak about the objective; however, everything that does not belong to the structure but to the material, everything that is ostended concretely, is in the end subjective ... If we aim, in spite of this, at agreement in the names given for the objects constituted on the basis of the 
experiences, then this cannot occur through reference to the completely diverging material but only through the formal indicators of the object-structures. (CARNAP, 1928, p. §16.)

From the perspective of structuralist metatheory, our empirical theories describe the structure of the material, to speak with Carnap's words. The tools of structuralist metatheory allow to represent all empirical theories as structural entities. Hence, there is a well-established distinction between these two levels. It is true that Worrall's use of 'nature' is somehow misleading, for it gives the debate a problematic and unnecessary metaphysical touch. But if we rely on Carnap's concept 'the material', I argue, we don't get that surplus flavor of metaphysical connotation.

It is well known that Carnap was not a realist, and that he aimed to stay neutral with his program, in the Aufbau as well as in his later works. Nevertheless, I see that Carnap's structuralist methodology of the Aufbau can be applied to epistemic structural realism. I argue with Carnap that, for the epistemic structural realist, only the structural components can be objective, since all other ways of describing our knowledge (e.g. via ostension) will end up being subjective, in Carnap's words. Now, if we put this into the context of epistemic structural realism, I want to recall that one of Worrall's main points in his 1989 paper is exactly that the terms to which we refer with our theories can change completely, and that we therefore should better focus on certain structural than on referential continuities. In this sense, I find Carnap's structuralist methodology helpful in order to strengthen epistemic structural realism. And in this way, such a distinction between structure and nature does make sense, without being inflationary or metaphysically unnecessary.

To the Structure-Loss Objection I propose the following answer. It is exactly through concrete case studies that one can show concrete cases of structure-loss. The same holds for the inverse case, i.e. one can also show how a structural continuity looks like. It might well be the case that there exist cases of structural loss. But what the adherent of this objection is urged to do is to work out careful case studies on these supposed structural losses. The same, again, for the structural realist. And it is exactly the aim of this work to contribute to this with the case study of linguistics provided here. It can be seen that, with the approach I am proposing, the question of structural continuity becomes a matter of accumulating convincing case studies. I argue that, once we have a certain amount of case 
studies, we can at least make an inductive step in the way Laudan (1981) does it with the PMI, but hopefully towards the other direction.

It might well turn out that the result will be that there are more cases of losses than of continuities, but this is a question, I argue, which cannot be answered normatively, and must be pursued in a way of accumulating logical reconstructions of concrete cases of scientific change. The crucial point for the solution of the question of structural losses is concerned with the importance of every specific case-study. As the structural realist will have to find representative cases of structural continuities, the same holds for those arguing in favor of structural losses. Is the case of the continuity of structure from Fresnel's to Maxwell's theory convincing enough? Surely not. There is a need for more case-studies. At the end, both sides will have to argue for the importance of each case in question.

\section{Conclusion}

First, I introduced structural realism by mainly alluding to Worrall's work and distancing my position from OSR. I mentioned a series of critiques that had been made to structural realism. I argued that an adequate tool for characterizing epistemic structural realism in a clear way is by means of structuralist metatheory. By applying certain technical notions of this program, the notion of structural continuity can be understood in a broader sense as only in the sense of a reappearance of certain mathematical equations. The result helps both to clarify Worrall's original proposal and to amplify structural realism. I argued that the structuralist notion of reduction can be used to represent formally what structural realists mean by 'structural continuity'. It is clear that only after taking out further concrete case studies, structural realism will find its corroboration or refutation. These case studies have to be worked out of all scientific disciplines which provide representative cases of theory change. In this sense I have pointed out which way might be a promising one to pursue for both structural realists and its opponents in order to bring out clear results within the debate.

It should also be clear that by no means this work does aim to provide ultimate answers to all objections that have been raised against structural realism. Moreover, it is a specific proposal of how to approach epistemic structural realism with a focus on theory change in a new way in order to provide solutions to some of its problems. 


\section{REFERENCES}

ABREU, C.; LORENZANO, P. \& C. U. MOULINES. Bibliography of Structuralism III (1995-2012 and Additions). Metatheoria, v. 3, n. 2, p. 1-35, 2013.

BALZER, W.; MOULINES, C. U. \& J. D. SNEED. An architectonic for science. The structuralist program. Dordrecht: Reidel, 1987.

BLOOMFIELD, L. A Set of Postulates for the Science of Language. Language, v. 2, n. 3, p. 153-164, 1926.

Language. London: Allen and Unwin, 1933.

BOYD, R. On the Current Status of the Issue of Scientific Realism. Erkenntnis, v. 19, n. 1, p. 45-90, 1983.

BUENO, O. What is Structural Empiricism? Scientific Change in an Empiricist Setting, Erkenntnis, v. 50, n. 1, p. 59-85, 1999.

Empiricism, Scientific Change and Mathematical Change. Studies in History and Philosophy of Science, v. 31, n. 2, p. 269-296, 2000.

Structural Realism, Scientific Change, and Partial Structures. Studia Logica, v. 89, n. 2, p. 213-235, 2008.

Models of Reduction. Principia, v.13, n. 3, p. 269-282, 2009.

CARNAP, R. Der logische Aufbau der Welt. Hamburg: Felix Meiner, [1928] 1998.

CHAKRAVARTTY, A. Semirealism. Studies in History and Philosophy of Modern Science, v. 29, n. 3, p. 391-408, 1998.

CHAKRAVARTTY, A. Structuralism as a Form of Scientific Realism. International Studies in Philosophy of Science, v. 18, n. 2-3, p. 151-171, 2004.

DA COSTA, N. C. A. \& S. FRENCH. Science and Partial Truth. A Unitary Approach to Models and Scientific Reasoning. Oxford: Oxford University Press, 2003.

DIEDERICH, W.; IBARRA, A. \& T. MORMANN. Bibliography of structuralism II (1989-1994 and additions). Erkenntnis, v. 30, n. 3, p. 387-407, 1989.

Bibliography of structuralism II (1989-1994 and additions). Erkenntnis, v. 41, n. 3, p. 403-418, 1994.

DÍEZ, J. \& C. U. MOULINES. Fundamentos de filosofía de la ciencia. Barcelona: Ariel, 2008.

FRENCH, S. \& J. LADYMAN. Remodeling Structural Realism: Quantum Physics and the Metaphysics of Structure. Synthese, v. 136, n. 1, p. 31-56, 2003.

Perspectivas - Revista do Programa de Pós-Graduação em Filosofia da UFT - n. 2 - 2018 
FRIGG, R. \& I. VOTSIS. Everything you Always Wanted to Know about Structural Realism but Were Afraid to Ask. European Journal for Philosophy of Science, v. 1, n. 2, p. 227-276, 2011.

HARRIS, Z. Methods in Structural Linguistics. Chicago: The University of Chicago Press, 1957.

LADYMAN, J. What is Structural Realism? Studies in History and Philosophy of Science, v. 29, n. 3, p. 409-424, 1998.

LADYMAN, J. \& D. ROSS. Every Thing Must Go. Metaphysics Naturalized. Oxford: Oxford University Press, 2007.

LANDRY, M. E. \& P. D. RICKLES (eds.). Structural Realism. Structure, Object, and Causality. The Western Ontario Series in the Philosophy of Science, Vol. 77. Dordrecht, Heidelberg, London, New York: Springer, 2012.

LAUDAN, L. A Confutation of Convergent Realism. Philosophy of Science, v. 48, n.1, p. 19-49, 1981.

Beyond Positivism and Relativism. Boulder: Westview Press, 1996.

MOULINES, C. U. Cuatro tipos de desarrollo teórico en las ciencias empíricas. Metatheoria, v. 1, n. 2, p. 11-27, 2011.

POINCARÉ, H. Science and Hypothesis. Dover: New York. [1905] 1952.

PSILLOS, S. Scientific Realism: How Science Tracks Truth. Routledge: London, 1999.

Is structural realism possible? Philosophy of Science, v. 68 (Supplementary Volume), p. 13-24, 2001.

PUTNAM, H. Philosophical Papers, Vol. 1: Mathematics, Matter and Method. Cambridge: Cambridge University Press, 1975.

RUSSELL, B. The Problems of Philosophy. Oxford: Oxford University Press, [1912] 2009.

SMART, J. J. C. Philosophy and Scientific Realism. London: Routledge, 1963.

Dificulties for Realism in the Philosophy of Science. In COHEN, L. J. et al. (eds.). Logic, Methodology and the Philosophy of Science VI. Amsterdam: North-Holland Publishing Company, 1979, pp. 363-375.

SNEED, J. The Logical Structure of Mathematical Physics. Dordrecht: Reidel, 1971.

Structuralism and Scientific Realism. Erkenntnis, v. 19, n. 1, p. 345-370, 1983.

Perspectivas - Revista do Programa de Pós-Graduação em Filosofia da UFT - n. 2 - 2018 
STEGMÜLLER, W. The Structure and Dynamics of Theories. New York, Heidelberg, Berlin: Springer, 1976.

SUPPES. P. Introduction to Logic. New York: Dover, [1957] 1999.

ZAHAR, E. Poincaré's Philosophy: From Conventionalism to Phenomenology. Chicago, La Salle: Open Court Publishing Co., 2001.

WORRALL, J. Structural Realism. The Best of Both Worlds? Dialectica, v. 43, n. 1-2, p. 99-124, 1989.

WORRALL, J. \& E. ZAHAR. Ramsification and structural realism. In ZAHAR, E. Poincaré's Philosophy: From Conventionalism to Phenomenology. Chicago, La Salle: Open Court Publishing Co., 2001, pp. 236-251. 